\title{
Preoperative Imaging Evaluation to Safeguard Anomalous Vertebral Artery in Posterior C2 Fixation
}

\author{
Hao Zhang ${ }^{1 *}$, Xinle Luo ${ }^{1}$, Shaochu Chen ${ }^{1}$, Jianhua Zhou ${ }^{1}$, Yawei Hu ${ }^{1}$, Wang Zhang ${ }^{1}$, Zengfeng Guo ${ }^{1}$ and Ming Gong ${ }^{1,2}$ \\ ${ }^{1}$ Department of Spine Surgery, Longhua People's Hospital, Southern Medical University, China
}

${ }^{2}$ Department of Spinal Surgery, Orthopaedic Research Institute, Hospital of Sun Yat-sen University, China

*Corresponding author: Hao Zhang, Department of Spinal Surgery, People's hospital of Longhua, Shenzhen, 518100, P. R. China

Received: 眥January 24, 2020

Published: 紫February 05, 2020

\begin{abstract}
Several variations of the $\mathrm{V} 3$ segment of the vertebral artery and narrow pedicles have been common observed and may complicate posterior C2 fixation. The drawback of pedicle screw (PS) fixation is a potential risk of vertebral artery (VA) injury, especially with a high-riding type. We report 12 patients with high-riding vertebral artery that underwent successful C2 fixation. Preoperative evaluation identified anomalous vertebral artery course and we recommend a thorough preoperative imaging evaluation with CT sagittal reconstruction, axial scan and CT angiography. This evaluation is indispensable, before posterior C0-2 or C1-2 surgery, allowing a better understanding of the vertebral artery variations, in order to minimize the risks of misplacement of cervical screw.
\end{abstract}

Keywords: Preoperative Imaging Evaluation; Anomalous Vertebral Artery; Posterior Cervical Fixation

\section{Introduction}

Posterior occipitocervical or atlantoaxial fixation and fusion procedures using C2 pedicle or short par or laminar screws instrumentation is widely used to treat patients with atlantoaxial dislocation or instability [1-4]. As injury rate of vertebral artery has been reported to be as high as $8.2 \%$ [1], the presence of an anomalous artery in patients increases the risk of jeopardizing it in operation [2-5]. The fixation process can result in potentially catastrophic results such as vertebrobasilar insufficiency and posterior fossa infarct, and even death [2]. Moreover, the artery injuries commonly occur if a drill or screw perforates or occludes the artery in the groove of $\mathrm{C} 2$, which is located on the lower surface of $\mathrm{C} 2$ and lateral to the pedicle [6,7]. Anatomical studies of the atlantoaxial region reported up to $5 \%$ anomalous vertebral artery (VA) and 18\% high-riding transverse foramen [8]. The knowledge of vertebral artery injury with C1-2 screw fixation or C2 pedicle screw placement is important, as it would provide surgeons with information on which to choose the appropriate fixation method preoperatively [9], particularly in cases of a high-riding vertebral artery or narrow pedicle [5-10]. Some researches had compared the risk of VA injuries by trans articular screw versus pedicle screw that anatomic risk of VA injury was not significantly different between trans articular and pedicle screws, contrary to the previous suggestion favoring pedicle screw [8-12]. However, we are aware preoperative imaging evaluation with CT sagittal reconstruction, axial scan and CT angiography can allow a better understanding of the vertebral artery variations $[13,14]$. A $3 \mathrm{D}$ evaluation is essential for establishing the anatomic relationship between the course of VA and the intended screw trajectory. It may be even more important to evaluate the risk of VA injury in those with a relatively small space to accommodate these screws [6-13]. Given the limitations of the studies, the primary purpose was to illustrate the anatomic risk of VA groove violation by computed tomography (CT) scan images to protect those with a high-riding vertebral artery and help to design treatment strategy.

\section{Clinical Material and Methods \\ Patient population}

Between July 2016 and February 2018, 12 consecutive patients were treated with 1-mm fine-slice C1-2 CT scans on one high-speed spiral CT scanner (General Electric Corp., Milwaukee, WI). The age and sex of each patient were recorded; every patient presented with an unstable C1-2 junction on the preoperative CT scan. Instability was additionally verified with flexion/extension radiographs and a screw trajectory reconstruction was obtained for each patient and 
preoperative performed. After surgery, patients were scheduled for an appointment in our outpatient department to undergo clinical follow-up examination 6 months after surgery.

\section{Surgical strategy}

In all patients, $\mathrm{C}-1$ lateral mass screws and $\mathrm{C}-2$ pedicle screws or short par screws or laminar screws or trans articular screws were chosen placed to stabilize the C1-2 segment. Either screw-plate or screw-rod and auto-graft fusion was applied in operation. The complete surgical procedure was performed according to the spinal instrumentation using the preoperative CT scanner. Each patient was placed prone on the carbon fiber surgical table (TruSystem 7500, Trumpf Medical Inc.) with the head fixed with Gasslie skull traction. Unstable pathology of C1-2 was reduced using traction or transoral release to restore the physiological configuration of the C1-2 pathology. In addition to traditional axial slices with coronal and sagittal reconstructions, a special screw trajectory reconstruction was obtained for each patient and performed before operation. Navigation CT scan, which is usually performed with the patient supine, may be critical as the anatomical landmarks for avoiding VA injury. Following the verification of accuracy, C1 lateral mass screws and C2 pedicle screws or short par screws or laminar screws or trans articular screws were placed. Moreover, for those patients with VAHR, short pars/laminar screw/trans articular screw was probably considered for C2 fixation. Or pedicle screw was another choice. In all cases, the navigated screw trajectory was designed on the C1-2 segment. Anatomical Analysis. All patients underwent cervical CT scan before the operation. The diameter of the pedicle of the axis as well as the distance between the vertebral canal and the spinal canal at the $\mathrm{C}-1$ level was retrospectively measured. The $\mathrm{C}-2$ pedicle diameter was defined as the minimum width ventral to the inferior articular facet of $\mathrm{C}-2$ and dorsal to the superior articular facet.

\section{Results}

\section{Patient population}

5 female and 7 male patients, with a mean age of $37.3 \pm 18.8$ years, were analyzed in our study. 10 patients suffered from atlantoaxial Dislocation (AAD), while 2 patients were diagnosed with atlantoaxial instability (AAI), which induced instability of the atlantoaxial junction (Table 1). All patients had complained about neck pain without radicular pain but no preoperative neurological deficit. Surgical indication was based on a preoperative cervical CT scan and MR image in all patients. The HRVA was verified with vascular diagnostics (CT angiography).

Table 1: Summary of Data for 8 Patients with Anomalous Course of Vertebral Artery at the Hybrid Fixations for Atlantioaxial Dislocation or Instability.

\begin{tabular}{|c|c|c|c|c|c|c|c|}
\hline No. & Age /Sex & Diagnosis & $\begin{array}{l}\text { JOA score } \\
\text { (pre-op) }\end{array}$ & $\begin{array}{l}\text { JOA score } \\
\text { (post-op) }\end{array}$ & High-Riding VA & $\begin{array}{l}\text { Asymmetry of } \\
\text { BL Vas }\end{array}$ & Method of Surgery \\
\hline 1 & $61 / \mathrm{M}$ & AAD & 12 & 15 & $+\mathrm{L}$ & $+(\mathrm{L}>\mathrm{R})$ & $\begin{array}{l}\text { C1-C2 fusion, C2 margel screw (R) and } \\
\text { short pars screw (L) }\end{array}$ \\
\hline 2 & $34 / F$ & $\mathrm{AAD}$ & 11 & 14 & $+\mathrm{R}$ & $+(\mathrm{R}>\mathrm{L})$ & Occ-C2 fusion, C2 PS (L) and LS (R) \\
\hline 3 & $11 / \mathrm{M}$ & AAI & 13 & 16 & $+\mathrm{R}$ & $+(\mathrm{R}>\mathrm{L})$ & Occ-C2 fusion, C2 PS (L) and LS(R) \\
\hline 4 & 29/M & $\mathrm{AAD}$ & 11 & 15 & $+\mathrm{R}$ & $+(\mathrm{L}>\mathrm{R})$ & Occ-C2 fusion, C2 PS (L) and LS (R) \\
\hline 5 & $77 / \mathrm{M}$ & $\mathrm{AAD}$ & 11 & 15 & $+\mathrm{L}$ & $+(\mathrm{R}>\mathrm{L})$ & Occ-C2 fusion, C2 PS (L) and LS (R) \\
\hline 6 & 28/M & AAI & 13 & 16 & $+\mathrm{R}$ & $+(\mathrm{R}>\mathrm{L})$ & C1-C2 fusion, C2 PS (L) and LS (R) \\
\hline 7 & $25 / \mathrm{F}$ & AAD & 12 & 15 & $+\mathrm{R}$ & $+(\mathrm{R}>\mathrm{L})$ & C1-C2 fusion, C2 PS (L) and LS (R) \\
\hline 8 & $34 / \mathrm{F}$ & AAD & 12 & 16 & $+\mathrm{R}$ & $+(\mathrm{R}>\mathrm{L})$ & C1-C2 fusion, C2 PS (L) and LS (R) \\
\hline 9 & $64 / F$ & $\mathrm{AAD}$ & 12 & 16 & $+\mathrm{L}$ & $+(\mathrm{L}>\mathrm{R})$ & C1-C2 fusion, C2 PS (R) and LS (L) \\
\hline 10 & $21 / \mathrm{F}$ & $\mathrm{AAD}$ & 12 & 15 & $+\mathrm{R}$ & $+(\mathrm{R}>\mathrm{L})$ & Occ-C2 fusion, C2 PS (L) and LS (R) \\
\hline 11 & 28/M & $\mathrm{AAD}$ & 12 & 15 & $+\mathrm{R}$ & $+(\mathrm{R}>\mathrm{L})$ & C1-C2 fusion, C2 PS (L) and LS (R) \\
\hline 12 & $36 / \mathrm{M}$ & $\mathrm{AAD}$ & 11 & 15 & $+\mathrm{R}$ & $+(\mathrm{R}>\mathrm{L})$ & C1-C2 fusion, C2 PS (L) and LS (R) \\
\hline
\end{tabular}

VA indicates vertebral artery; AAD: Atlantoaxial Dislocation; AAI: Atlantoaxial Instability, L: left; R: Right; Occ-C: Occipitocervical; PS: Pedicle Screws; LS: Lamnial Screw

\section{Illustrative case}

Twenty-five years ago, a 61-year-old man had a neck-injure without any medical care. He complained of intense cervical pain for nearly 1 year without neurological deficit and he had no previous medical history. Upon initial clinical examination, the patient had intense cervical neck pain while slightly protruding to the left side. He was limited rotation activity and had no motor paralysis or sensory disturbance. There was no sign of any head injury or concussion and a negative Hoffman's sign. Radiograph revealed C1-2 atlantoaxial dislocation. Further investigation included a computed tomography (CT) scan, a magnetic resonance imaging (MRI) scan and a CT angiography (CTA). The CT scan showed odontoideum. 
Magnetic resonance tomography did not show any lesion of the anterior longitude ligament. The CTA for assessment of VA depicted the sinuous course of the third segment (V3) of VA between C1 and $\mathrm{C} 2$ as a right-side high-riding on artery groove of C2. C1 was displaced anteriorly relative to $\mathrm{C} 2$, with bilateral displacement of the lateral joints (Figures 1A, B). CT and magnetic resonance (MR) angiography revealed a displaced odontoideum (Figures $2 \mathrm{~B}$ ) and bilateral dislocation of the C1-C2 facet joint (Figures 2A, C). In the left-side of C2 level, it showed a high-riding vertebral artery (VA) as axial CT indicated (Figure 2D). The CTA for assessment of VA depicts the sinuous course of the V3 segment of VA between C1 and $\mathrm{C} 2$ as a "high-riding" on the vertical groove of C2 (Figure 2E). We decided to perform surgery to reduce the dislocation and fix the C1-C2 joint.
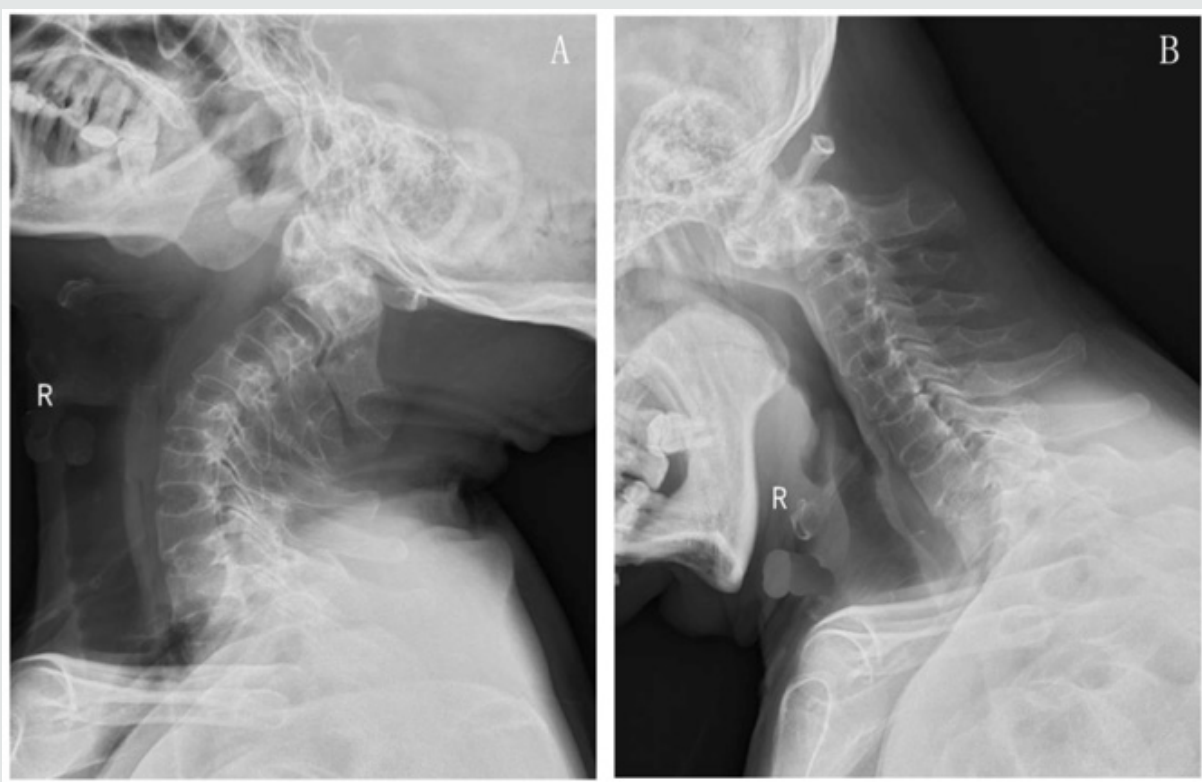

Figure 1: Plain lateral radiograph of cervical spine reveals notable degenerative changes of $\mathrm{C} 1-2$, osteoporosis and os odontoideum. X-ray images showed extension (A) and flexion (B) that C1-2 dislocation.
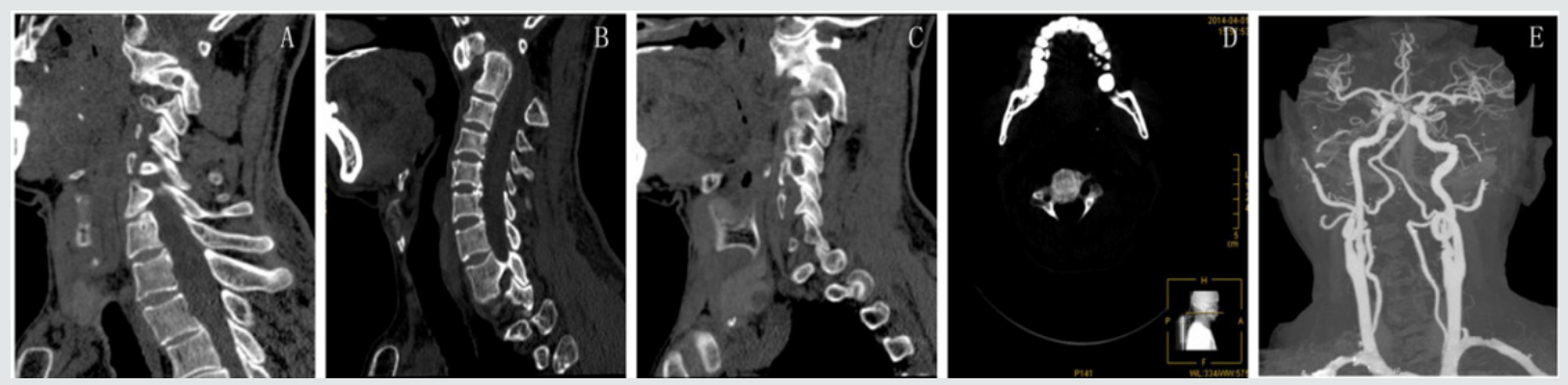

Figure 2: Sagittal computed tomography (CT) reconstruction images before surgery. Posteriorly displaced odontoideum (B) and bilateral dislocation of the C1-C2 facet joint (A and C) were prominent. To the left of C2, a high-riding vertebral artery (VA) was revealed (A; arrow) and axial CT scan showed left (D). The CTA for assessment of VA depicts the sinuous course of the V3 segment of VA between C1 and C2 as a "high-riding" on the vertical groove of C2 (E).

\section{Treatment strategy}

The patient was given general anesthesia and treated in the supine position initially. The anterior longitudinal ligament and the longus colli and longus capitis were released subsequently through transoral approach, and then, atlantoaxial facet joint capsule was cut off. However, atlantoaxial dislocation was not reduced successfully. Next, in prone position, a pars screw was placed on the right side at C2 (Figure 3A and B). Since a high-riding VA was seen on the left side of $\mathrm{C} 2$, a laminar screw was placed on the left. On the right side of $\mathrm{C} 1$, we chose a uni-cortical lateral Margel screw via the posterior arch (Figure 3B). Because a lateral Margel screw placed at that location could put the osteoporotic patient at risk for a dominant VA injury if the screw ever loosened. Fluoroscopy was used in the operation to confirm the correct placement of the hardware and the anatomic alignment. Postoperatively, the patient was immobilized in halo vest (Figure 3C). 

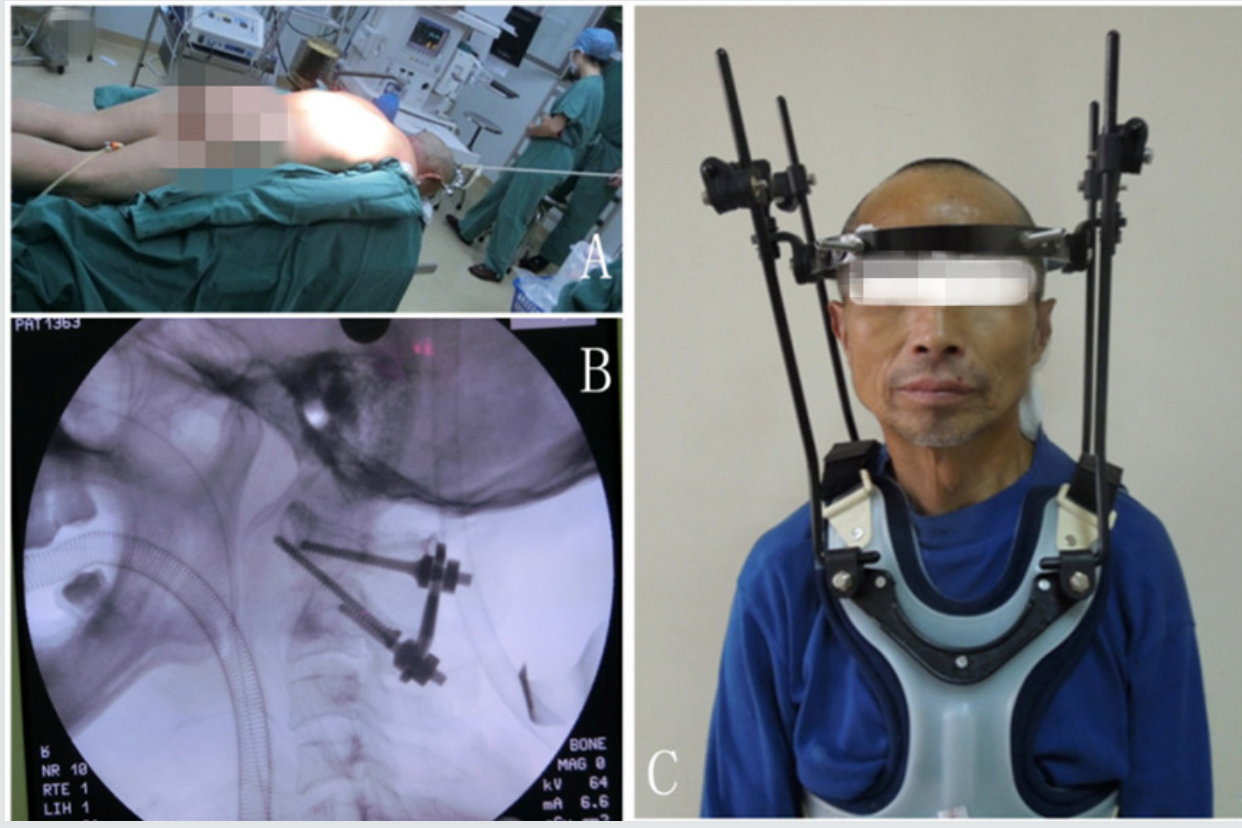

Figure 3: The patient was treated in the prone position with consisting traction (A). Fluoroscopy was used in operation to confirm the correct placement of the hardware, a uni-cortical lateral margel screw of $\mathrm{C} 1$, a uni-cortical laminar screw on left and a pars screw was placed on the right side at C2.(B) The patient was immobilized in halo vest postoperatively for three months (C).

\section{Follow-up}

One week after the surgery, radiography revealed posterior fixation and reduced C1-C2 dislocation. X-ray and CT images showed the position of C1 mass screw and C2 laminar screw and margel screw (Figure 4 and 5). And 3 months later, the halo vest was removed, and C1-2 reduction was maintained. Moreover, the MR image confirms cervical decompression of the C1-2 spinal canal level (Figure 6A-C). The patient was in good condition, only a slight weakness when trying to abduct his bilateral fingers. Written informed consent was obtained from the patient for publication of this case report and any accompanying images.
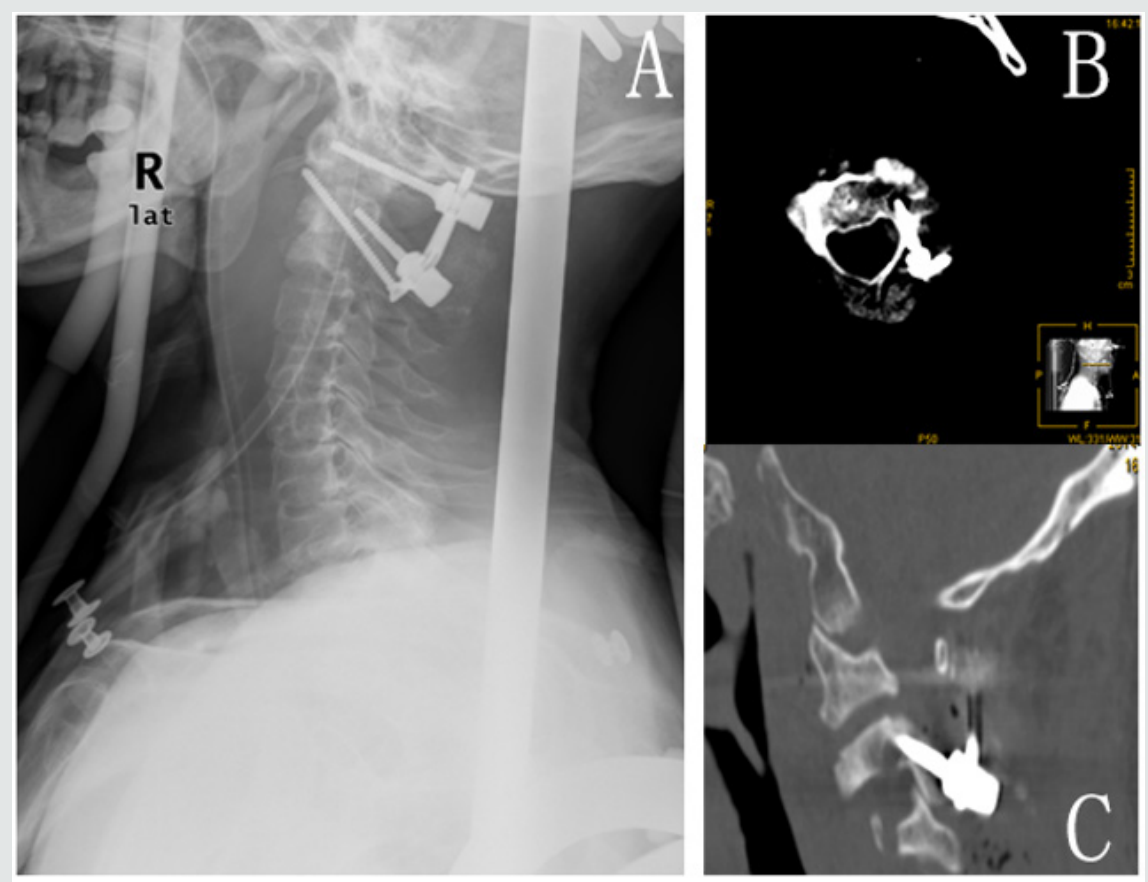

Figure 4: X-ray and computed tomography (CT) images after surgery for 1 week. Radiography revealed posterior fixation and reduced C1-C2 dislocation (A). Axial CT images showed mass screw and laminar screw and margel screw at C2 (B). Sagittal CT images showed posterior laminar screw (C). 

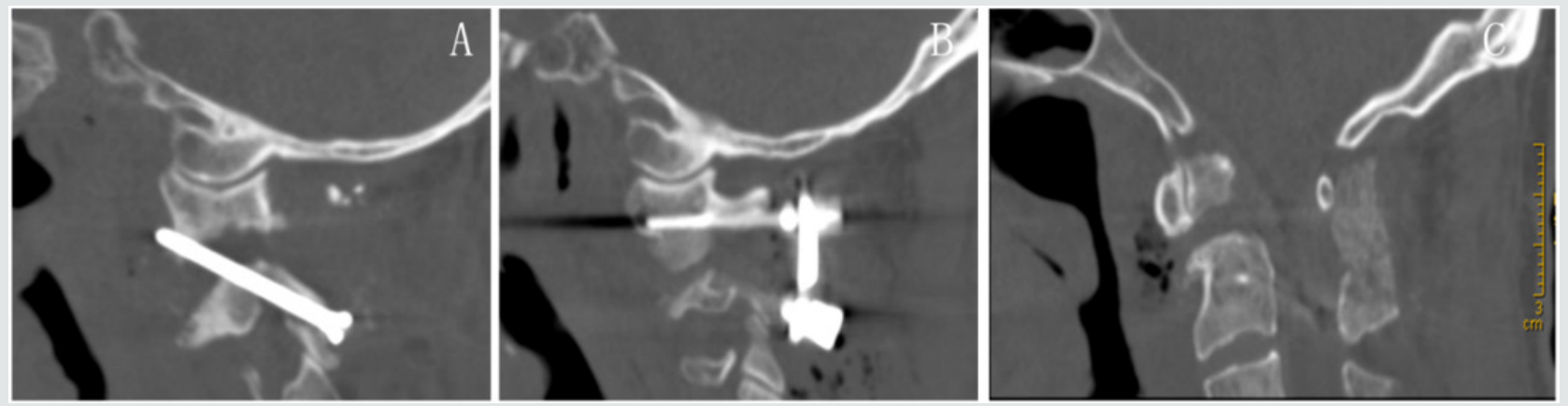

Figure 5: Sagittal CT images of 1 week after the surgery. The C1-2 reduction was maintained (A, C) and the displaced odontoideum (B).
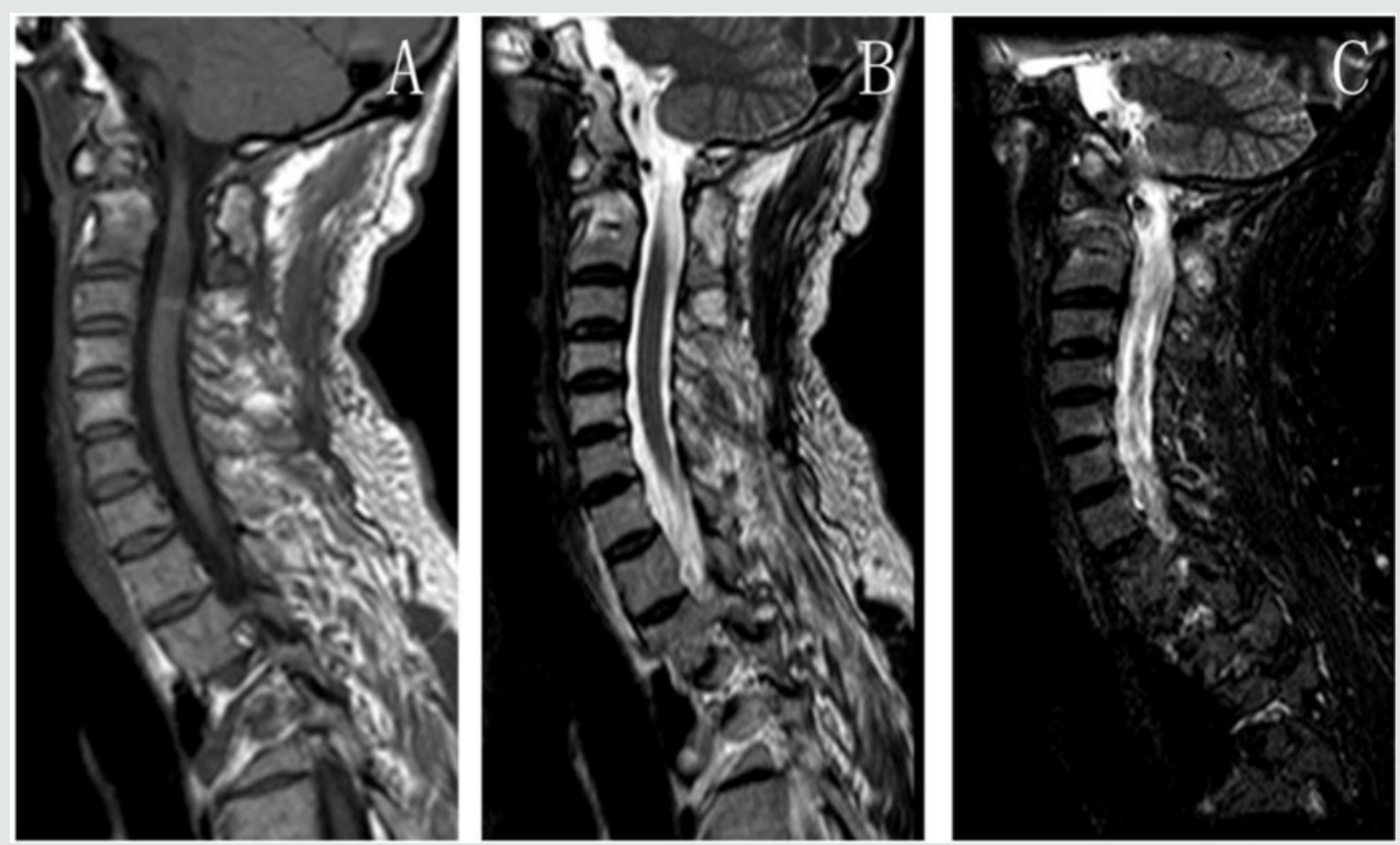

Figure 6: MRI scan of the cervical spine after 3 months of surgery, the T2-weighted image (B) confirms the above findings as well as T1-weighted image (C) indicates cervical decompression of the C1-2 spinal canal level.

\section{Discussion}

In the surgical treatment of upper cervical spine, the anchor screw for C1 stabilization has been lateral mass screws and pedicle or short pars or laminar screws for C2 [8-15]. However, in our cases, the patients were elderly, with sinuous course of the third segment (V3) of VA as a right-side high-riding, which make the insertion a challenging and prone to potentially catastrophic complications such as VA injury. To avoid such complications, it is recommended that C2 pedicel screw insertion should be abandoned in patients with one side HRVA. Therefore, surgeons should pay careful preoperative attention to the presence of abnormal VA. The original concept of a HRVA was based on the trajectory of atlantoaxial trans articular screws (TAS) [16]. In previous reports of atlantoaxial TAS, a HRVA was described as a "large VA groove", and a "high-riding transverse foramen" was noted to be associated with additional risk for insertion of atlantoaxial TAS. [1] The term "high riding VA" was first used by Song et al. in 1997 [17]. He defined a HRVA when the height of the $\mathrm{C} 2$ pedicle isthmus was $65 \mathrm{~mm}$ and/or the internal height was $62 \mathrm{~mm}$ on a sagittal image that is $3 \mathrm{~mm}$ lateral to the cortical margin of the spinal canal wall at C2. However, this definition was based on the trajectory of a TAS, and it is uncertain if this definition can be applied to assess the feasibility of safely inserting a C2 pedicel or laminar screw. We analyze the morphology of the $\mathrm{C} 2$ pedicle from the perspective of the screw trajectory and reveal the relationship between the feasibility of safely inserting a C2 PS and the presence of a HRVA. Using conventional axial CT scans with perpendicular reconstructions [18], we have found enough anomalies to prevent us from placing bilateral screws in the patients undergoing atlantoaxial screw fixation. This finding led to the present review of a consecutive series of trauma patients undergoing fine-slice C1-2 CT scanning [19]. The screw trajectory reconstruction was devised to assist in evaluating the information derived from the CT scan in the most efficient manner [4-20]. This study supports our clinical findings that approximately $20 \%$ of patients will have a high-riding transverse foramen on at least one side [15]. Although there is no guarantee that the VA is actually 
in the foramen where the screw would cross, we have chosen not to place screws in these instances. In such cases CT angiography or three-dimensional CT might be able to trace the course of the VA more accurately. In treatment, our findings indicate that the anatomy of patients is suitable for hybrid screw fixation.

The screw trajectory reconstruction is easily performed on CT scanners with spiral software.[14] The patients undergo scanning in the traditional supine position, with 1-mm thick reconstructions based on the axial images. The ability to view the entire screw path on one image allows subtleties such as the lateral-pedicle screw trajectory, which are critical to planning the procedure, to be more readily appreciated. Hybrid screw fixation of the atlantoaxial joint is becoming a routine procedure. The development of better imaging modalities has made it easier to recognize a subset of patients in whom this procedure may be appropriate. Careful scrutiny of the VA will enable the surgeon to avoid inflicting a potentially catastrophic injury when this procedure is performed.

\section{Conclusion}

The presented cases describe the clinical, but mostly multiple morphologic variations that have not yet been reported. The already high rate of anatomical variations of the VA is probably becoming even greater when or another osseous anomaly is diagnosed. Thus, we recommend a thorough preoperative imaging evaluation, with CT scan and CT angiography, in addition to plain radiographs. This evaluation is imperative, before a cervical spine surgery, allowing a better understanding of the anatomy, in order to minimize the risks of misplacement of cervical instrumentation especially in such patients.

\section{Conflicts of Interest}

The authors hereby declare that they have no conflicts of interest.

\section{Acknowledgement}

This work was supported by Science and Technology of Longhua specific fund (2017008); Sanming Project of Medicine in Shenzhen (SZSM201609028); Special funds for the construction of key disciplines funded projects in Longhua District, Key program of National Natural Science Foundation of China (No.31430030) and National Natural Science Foundation of China (Grant No. 81600606).

\section{References}

1. Wright NM, Lauryssen C (1998) Vertebral artery injury in C1-2 transarticular screw fixation: results of a survey of the AANS/CNS section on disorders of the spine and peripheral nerves. American Association of Neurological Surgeons/Congress of Neurological Surgeons. J Neurosurg 88(4): 634-640.

2. Gluf WM, Schmidt MH, Apfelbaum RI (2005) Atlantoaxial transarticular screw fixation: a review of surgical indications, fusion rate, complications, and lessons learned in 191 adult patients. J Neurosurg Spine 2(2): 155163.

3. Kotil K, Muslumanoglu M (2014) C1-2 posterior arthrodesis technique with a left segmental and right transarticular fixation. A hybrid novel (Kotil) technique. J Craniovertebr Junction Spine 5(2): 102-105.
4. Hong JT, Jang WY, Kim IS, Yang SH, Sung JH, et al. (2011) Posterior C1 stabilization using superior lateral mass as an entry point in a case with vertebral artery anomaly: technical case report. Neurosurgery 68(1): 246-249.

5. Inamasu J, Kim DH, Klugh A (2005) Posterior instrumentation surgery for craniocervical junction instabilities: an update. Neurol Med Chir 45(9): 439-447.

6. Sciubba DM, Noggle JC, Vellimana AK, Alosh H, McGirt MJ, et al. (2009) Radiographic and clinical evaluation of free-hand placement of $\mathrm{C}-2$ pedicle screws. Clinical article. J Neurosurg Spine 11(1): 15-22.

7. Kandziora F, Schulze Stahl N, Khodadadyan Klostermann C, Schroder $\mathrm{R}$, Mittlmeier T (2001) Screw placement in transoral atlantoaxial plate systems: an anatomical study. J Neurosurg 95(1): 80-87.

8. Paramore CG, Dickman CA, Sonntag VK (1996) The anatomical suitability of the C1-2 complex for transarticular screw fixation. Journal of neurosurgery 85(2): 221-224.

9. Richter M, Mattes T, Cakir B (2004) Computer-assisted posterior instrumentation of the cervical and cervico-thoracic spine. European spine journal: official publication of the European Spine Society, the European Spinal Deformity Society, and the European Section of the Cervical Spine Research Society 13(1): 50-59.

10. Kawaguchi Y, Ishihara H, Ohmori K, Kanamori M, Kimura T (2002) Computer-assisted Magerl's transarticular screw fixation for atlantoaxial subluxation. J Orthop Sci 7(1): 131-136.

11. Han C, Yang QG, Zhang JX, Hua XY, Zhang YS, (2010) The application of C1-2 pedicle screw fixation in treating atlantoaxial instability. Zhongguo Gu Shang 23(7): 544-546.

12. Ringel F, Reinke A, Stuer C, Meyer B, Stoffel M (2012) Posterior C1-2 fusion with C1 lateral mass and C2 isthmic screws: accuracy of screw position, alignment and patient outcome. Acta Neurochir (Wien) 154(2): 305-312.

13. Chern JJ, Chamoun RB, Whitehead WE, Curry DJ, Luerssen TG, et al. (2009) Computed tomography morphometric analysis for axial and subaxial translaminar screw placement in the pediatric cervical spine. J Neurosurg Pediatr 3(2): 121-128.

14. Czabanka M, Haemmerli J, Hecht N, Foehre B, Arden K, et al. (2017) Spinal navigation for posterior instrumentation of C1-2 instability using a mobile intraoperative CT scanner. J Neurosurg Spine 27(3): 268-275.

15. Madawi AA, Casey AT, Solanki GA, Tuite G, Veres R, et al. (1997) Radiological and anatomical evaluation of the atlantoaxial transarticular screw fixation technique. J Neurosurg Spine 86(6): 961-968.

16. Nazemi AK, Bickley SR, Behrend CJ, Carmouche JJ (2017) C1-2 Fixation Approach for Patients with Vascular Irregularities: A Case Report. Geriatr Orthop Surg Rehabil 8(4): 263-267.

17. Song GS, Theodore N, Dickman CA, Sonntag VK (1997) Unilateral posterior atlantoaxial transarticular screw fixation. J Neurosurg Spine 87(6): 851-855.

18. Sorimachi Y, Iizuka H, Ara T, Nishinome M, Iizuka Y, et al. (2011) Atlantoaxial joint of atlanto-axial subluxation patients due to rheumatoid arthritis before and after surgery: morphological evaluation using CT reconstruction. Eur Spine J 20(5): 798-803.

19. He S, Ye C, Zhong N, Yang M, Yang X, et al. (2019) Customized anterior craniocervical reconstruction via a modified high-cervical retropharyngeal approach following resection of a spinal tumor involving C1-2/C1-3. J Neurosurg Spine pp.1-9.

20. Hwang IC, Kang DH, Han JW, Park IS, Lee CH, et al. (2007) Clinical experiences and usefulness of cervical posterior stabilization with polyaxial screw-rod system. J Korean Neurosurg Soc 42(4): 311-316. 
(C) (P) This work is licensed under Creative

To Submit Your Article Click Here: Submit Article

DOI: $10.32474 /$ OSMOAJ.2020.03.000166

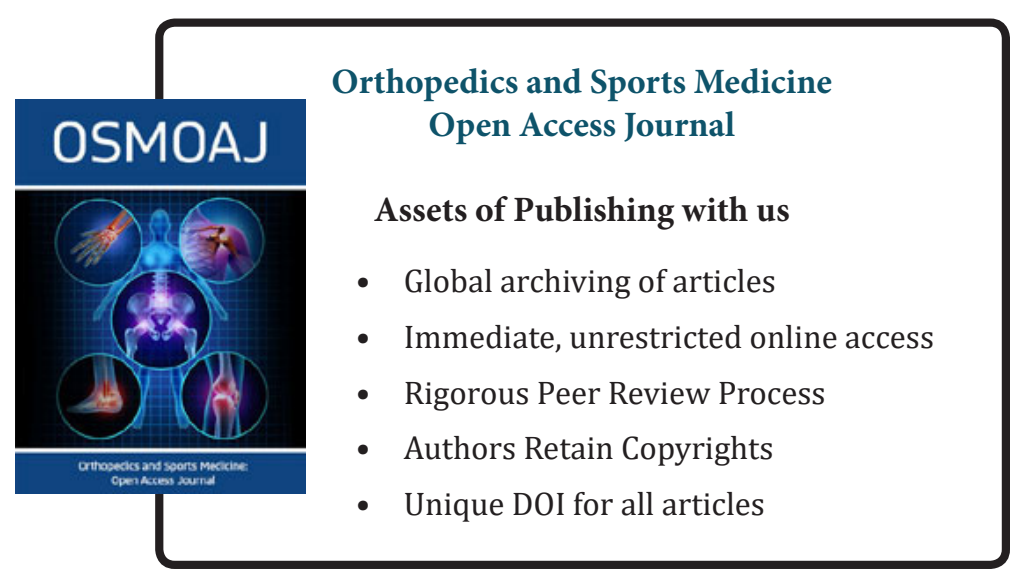

